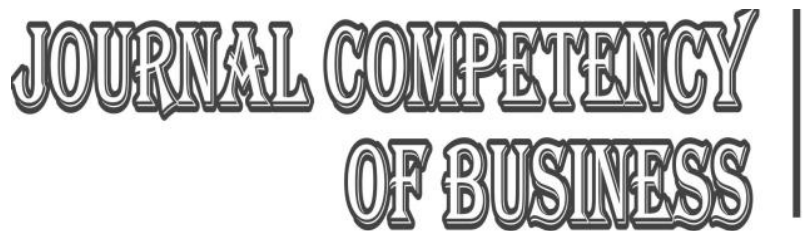

\title{
PENGARUH PERPUTARAN MODAL KERJA, DAN PROFITABILITAS TERHADAP KINERJA KEUANGAN PADA BMT SYARIAH DI JALAN VETERAN YOGYAKARTA
}

\author{
Ika Nur Yuliningsih ${ }^{1}$, Risal Rinofah $^{2}$ \\ ${ }^{1,2}$ Fakultas Ekonomi Universitas Sarjanawiyata Tamansiswa Yogyakarta \\ e-mail: ikanuryuliningsih16@gmail.com
}

\begin{abstract}
Abstrak
Tujuan penelitian ini adalah untuk mengkaji: (1) pengaruh secara parsial perputaran modal kerja terhadap kinerja keuangan, (2) pengaruh secara parsial profitabilitas terhadap kinerja keuangan, dan (3) pengaruh secara simultan perputaran modal kerja dan profitabilitas terhadap kinerja keuangan pada BMT Syariah di Jalan Veteran Yogyakarta. Penelitian ini terkait dengan penggunaan metode kuantitatif, inferensi deskriptif dan metode analisis statistik. Teknik pengumpulan data menggunakan laporan keuangan triwulanan BMT Syariah di Jalan Veteran Yogyakarta yang dirilis dari Januari 2015 sampai Desember 2019. Teknik analisis data menggunakan analisis regresi berganda. Hasil penelitian menunjukkan bahwa ada (1) pengaruh secara parsial perputaran modal kerja terhadap kinerja keuangan. (2) Ada pengaruh secara parsial profitabilitas terhadap kinerja keuangan. (3) Ada pengaruh secara simultan perputaran modal kerja dan profitabilitas terhadap kinerja keuangan.
\end{abstract}

\section{Kata kunci: modal kerja, profitabilitas, kinerja keuangan}

\section{Abstract}

The purpose of this study was to examine: (1) the partial effect of working capital turnover on financial performance, (2) the partial effect of profitability on financial performance, and (3) the simultaneous effect of working capital turnover and profitability on financial performance at BMT Syariah in Yogyakarta Veterans Street. This research is related to the use of quantitative methods, descriptive inference and statistical analysis methods. The data collection technique used the quarterly financial reports of BMT Syariah on Jalan Veteran Yogyakarta which was released from January 2015 to December 2019. The data analysis technique used multiple regression analysis. The results showed that there was (1) partial effect of working capital turnover on financial performance. (2) There is a partial effect of profitability on financial performance. (3) There is a simultaneous effect of working capital turnover and profitability on financial performance.

Keywords: working capital, profitability, financial performance

\section{PENDAHULUAN}

Perbankan ialah suatu sarana yang strategis dalam rangka pembangunan ekonomi suatu negara.kiprah yang strategis tersebut terutama disebabkan bank menjadi penghimpun serta penyalur dana dari rakyat secara efektif serta efisien buat mencapai tujuan pembangunan nasional. Dalam usaha membantu memperbaiki taraf hidup orang banyak, maka lembaga perbankan sudah menunjukkan perkembangan yang sangat baik.

Berdasarkan Zainul Arifin (2009:12), sebagai negara yang mempunyai komunitas Muslim terbesar serta secara formal telah membuatkan keuangan syariah atas dasar undang- 
Fakultas Ekonomi, Universitas Cokroaminoto Yogyakarta

undang dan tuntutan kebutuhan warga, Indonesia telah terlibat secara aktif pada berbagai lembaga kerjasama Internasional dibidang keuangan dan perbankan syariah. buat mendirikan forum ini perlu didukung aspek permodalan yang bertenaga. Modal merupakan faktor yang sangat krusial bagi perkembangan dan kemajuan bank sekaligus menjaga kepercayaan rakyat. Setiap penciptaan aktiva, disamping berpotensi membuat keuntungan pula berpotensi menimbulkan terjadinya resiko kerugian jika tidak dikelola dengan baik.

Berdasarkan Suad Husnan (1995:77), bank bisa dikatakan memiliki kinerja yang baik ialah dengan melihat seberapa efisien bank tadi pada mengelola asset dan modal yang dimiliki.. Aktiva lancar artinya aktiva yang akan bermetamorfosis sebagai uang kas dalam satu periode akuntansi yakni satu tahun. Didalam penjelmaan aktiva lancar itu sebagai uang kas melewati beberapa tahap.Tahapan-tahapan itu tercermin dalam pos-pos neraca.

Pengertian kinerja Indra Bastian (2006: 274) adalah gambaran tentang implementasi / rencana / implementasi kebijakan untuk mencapai tujuan, sasaran, misi dan visi organisasi.Menurut Indriyo Gitosudarmo dan Basri (2002: 275) konsep kinerja keuangan adalah rangkaian aktivitas keuangan dalam kurun waktu tertentu yang dilaporkan dalam laporan keuangan, termasuk laporan laba rugi dan neraca. Menurut Irhan Fahmi (2011: 2), kinerja keuangan merupakan analisis yang bertujuan untuk memahami sejauh mana suatu perusahaan telah menerapkan aturan pelaksanaan keuangan yang benar dan benar.

Perputaran modal kerja adalah keliru satu rasio buat mengukur atau menilai keefektifan modal kerja perusahaan selama periode tertentu. Semakin pendek periode perputaran modal kerja berarti semakin cepat atau semakin tinggi taraf perputaran modal kerja dan semakin efisien penggunaan modal kerja itu sebagai akibatnya mempertinggi profitabilitas. Kinerja keuangan dapat dipandang asal perbandingan laba dengan asal daya keuangan yang dilibatkan pada perjuangan itu sendiri. Profitabilitas dapat menandakan kemampuan manajemen dalam mengelola sumber daya secara efisien.galat satu sumber daya yang paling krusial dalam perusahaan artinya modal.

Sutrisno (2007: 39) menjelaskan pengertian modal kerja sebagai berikut: "Modal kerja adalah dana yang digunakan perusahaan untuk memenuhi kebutuhan sehari-hari, seperti membeli bahan baku, membayar tenaga kerja, melunasi hutang dan pembayaran lainnya".Saat mengevaluasi efektivitas modal kerja, rasio antara penjualan dan perputaran modal kerja dapat digunakan. Tingkat perputaran modal kerja yang rendah menunjukkan adanya modal kerja yang terlalu banyak, yang mungkin disebabkan oleh persediaan yang rendah, tingkat perputaran piutang atau saldo kas yang berlebihan. (Munawir, 2000: 80).

Modal dalam rasio profitabilitas merupakan modal yang digunakan buat membentuk untung, modal tadi dapat berasal berasal modal sendiri ataupun hutang menjadi modal asing.Profitabilitas yang dihitung dari membandingkan untung dengan modal asing serta modal sendiri dianggap profitabilitas ekonomi, sedangkan rentabiitas yang dihitung dari membandingkan untung dengan modal sendiri saja diklaim profitabilitas modal sendiri.bila modal kerja yang digunakan melebihi kebutuhan yang semestinya maka menyebabkan profitabilitas akan menurun. Jadi, modal kerja harus digunakan menggunakan sempurna sehingga tidak akan menjadi in-efisiensi dalam penggunaan modal kerja. 


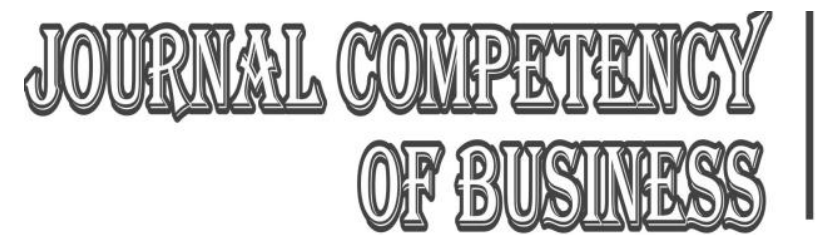

Fakultas Ekonomi, Universitas Cokroaminoto Yogyakarta

Profitabilitas suatu perusahaan merupakan rasio laba terhadap aset atau modal yang menghasilkan laba. Dengan kata lain profitabilitas adalah kemampuan suatu perusahaan untuk menghasilkan laba dalam kurun waktu tertentu (Bambang Riyanto, 2001: 35). Menurut Sofyan Syafri Harahap (2007), rasio profitabilitas (disebut juga profitabilitas) menggambarkan profitabilitas perusahaan melalui semua kapabilitas dan sumber daya yang tersedia (seperti aktivitas penjualan, kas, modal, jumlah karyawan, jumlah cabang, dll.)

Modal kerja serta retabilitas yang baik akan menentukan kinerja keuangan..taraf kesehatan bank merupakan nilai yang wajib dipertahankan oleh setiap bank, karena baik buruknya suatu bank maka akan mempengaruhi kepercayaan nasabah terhadap bank yang bersangkutan. buat mengetahui sehat atau tidaknya suatu bank, maka dapat ditinjau berasal laporan keuangan.

Laporan keuangan artinya penggambaran berita asal kinerja keuangan bank.Tujuan laporan keuangan merupakan memberikan info kepada pihak manajemen bank maupun pihak luar yang berkepentingan pada laporan tersebut.pada penelitian ini laporan keuangan yang digunakan merupakan neraca serta laporan untung rugi. Laporan keuangan neraca mendeskripsikan perihal posisi keuangan bank pada periode tertentu, sedangkan laporan laba rugi mendeskripsikan info perihal perkembangan perjuangan bank di suatu periode tertentu.

\section{METODE PENELITIAN}

Penelitian ini terkait dengan penggunaan metode kuantitatif, inferensi deskriptif dan metode analisis statistic.Penelitian ini menggunakan data pembantu dari laporan keuangan BMT Syariah di Jalan Veteran Yogyakarta.Variabel bebas dalam penelitian ini adalah perputaran modal kerja dan profitabilitas dan variabel terikat adalah kinerja keuangan.

Kinerja keuangan diamati dengan menganalisis rasio keuangan berikut untuk mengamati laporan keuangan tahunan perusahaan: kinerja keuangan menggunakan rasio keuangan modal diukur dengan rasio kecukupan modal (CAR).

WCTO merupakan rasio yang digunakan untuk mengukur atau mengevaluasi efektivitas modal kerja suatu perusahaan dalam kurun waktu tertentu. Kasmir (2008) mengukur tingkat perputaran modal kerja dengan membandingkan penjualan bersih dengan rata-rata modal kerja atau modal kerja. WCTO menggunakan rumus berikut untuk menghitung:$$
\text { WCTO }=\frac{\text { Penjualan Bersih }}{\text { Aktiva lancar }- \text { Hutang lancar }}
$$

Net interest margin (NIM) adalah rasio yang digunakan untuk mengukur kemampuan manajemen bank dalam mengelola aset yang menguntungkan untuk memperoleh bunga bersih. NIM dihitung menggunakan rumus berikut:

$\mathrm{NIM}=$ pendapatan bunga bank yang diperoleh -biaya bunga bank yang menjadi beban / rata-rata aktiva produktif yang digunakan x $100 \%$

Data populasi dan laporan keuangan BMT Syariah di Yogyakarta.Sampel penelitian ini adalah laporan keuangan triwulanan BMT Syariah di Jalan Veteran Yogyakarta yang dirilis 
Fakultas Ekonomi, Universitas Cokroaminoto Yogyakarta

dari bulan Januari 2015 sampai dengan Desember 2019. Laporan tersebut sesuai dengan standar PSAK.

Metode pengumpulan data yang digunakan dalam penelitian ini adalah metode dokumen laporan keuangan BMT syariah veteran Yogyakarta tahun 2015 hingga 2019. Teknik analisis data menggunakan analisis regresi ganda dengan rumus sebagai berikut:

$\mathrm{Y}=\mathrm{a} 1 \mathrm{bX} 1+\mathrm{a} 2 \mathrm{bX} 2+\mathrm{a} 3 \mathrm{bX} 3$

Keterangan:

$\mathrm{Y}=$ variabel dependen (kinerja keuangan)

a = harga konstan (harga Y ketika harga $\mathrm{X}=0$ )

$\mathrm{b} \quad=$ nilai-nilai variabel independen

$\mathrm{X} 1$ = variabel independen (modal kerja)

$\mathrm{X} 2$ = variabel independen (profitabilitas)

Analilisi Silmutan (Uji F)dilakukan untuk mengetahui pengaruh secara serentak variabel

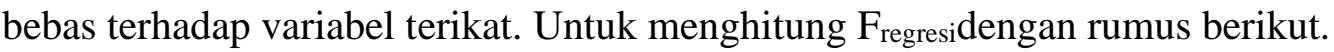

$$
\mathrm{F}_{\text {reg }} \frac{\mathrm{R}^{2}(\mathrm{~N}-\mathrm{m}-1)}{\mathrm{m}\left(1-\mathrm{R}^{2}\right.}
$$

Keterangan:
$\mathrm{R}^{2}=$ Koefisien determinasi
$\mathrm{m}=$ Jumlah variabel bebas
$\mathrm{n} \quad=$ Jumlah anggota sampel

Uji t dilakukan untuk menguji signifikansi konstanta dan variabel bebas dengan satu variabel terikat yaitu dengan rumus:

Keterangan:

$$
t_{\text {hitung }}=\frac{r \sqrt{n}-2}{\sqrt{1}-r^{2}}
$$

$\mathrm{t} \quad=$ Nilai hitung

$\mathrm{r} \quad=$ Koefisien korelasi hasil rxy

$\mathrm{n} \quad=$ Jumlah responden

\section{HASIL DAN PEMBAHASAN}

\section{Hasil Penelitian}

Analisis dalam penelitian ini adalah analisis regresi linier berganda. Analisis ini digunakan untuk mengetahui pengaruh variabel bebasa terhadap terikat. Berdasarkan hasil perhitungan dengan menggunakan program statistik komputer SPSSfor Windows diperoleh hasil sebagai berikut: 


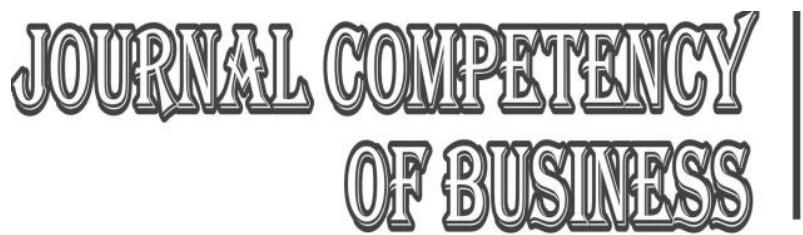

Tabel 1. Hasil Regresi Linier Berganda

Coefficients $^{\mathrm{a}}$

\begin{tabular}{|c|c|c|c|c|c|c|}
\hline \multirow{2}{*}{\multicolumn{2}{|c|}{ Model }} & \multicolumn{2}{|c|}{$\begin{array}{c}\text { Unstandardized } \\
\text { Coefficients }\end{array}$} & $\begin{array}{c}\text { Standardized } \\
\text { Coefficients }\end{array}$ & \multirow[t]{2}{*}{$t$} & \multirow[t]{2}{*}{ Sig. } \\
\hline & & B & Std. Error & Beta & & \\
\hline \multirow{3}{*}{1} & (Constant) & -643.366 & 110.824 & & -5.805 & .028 \\
\hline & $\begin{array}{l}\text { Perputaran modal } \\
\text { kerja }\end{array}$ & 21.215 & 4.036 & .759 & 5.256 & .034 \\
\hline & Profitabilitas & 660.038 & 111.135 & .858 & 5.939 & .027 \\
\hline
\end{tabular}

a. Dependent Variable: Kinerja keuangan

Sumber: Hasil Olah Data, 2021

Pada persamaan di atas ditunjukkan pengaruh variabel independen $(\mathrm{X})$ terhadap variabel dependen (Y). Adapun arti dari koefisien regresi tersebut adalah: $b_{1}=21,251$, artinya apabila kenaikan permutaran modal sebesar 1 persen, maka kinerja keuangan naik sebesar 21,251 rupiah dengan asumsi variabel lain adalah konstan (ceteris paribus). $\mathrm{b}_{2}=660,038$, artinya apabila kenaikanprofitabilitas sebesar 1 rupiah, maka kinerja keuangan naik sebesar 660,038 rupiah dengan asumsi variabel lain adalah konstan (ceteris paribus).

\section{Koefisien determinasi $\left(\mathbf{R}^{\mathbf{2}}\right)$}

Koefisien determinasi $\left(\mathrm{R}^{2}\right)$ pada intinya mengukur seberapa jauh kemampuan model dalam menerangkan variasi variabel dependen. Nilai koefisien determinasi adalah antara nol dan sampai dengan satu. Nilai adjusted $\mathrm{R}^{2}$ yang mendekati satu berarti kemampuan variabelvariabel independen memberikan hampir semua informasi yang dibutuhkan untuk memprediksi variasi variabel dependen (Ghozali, 2016). Hasil uji koefisien determinasi $\left(\mathrm{R}^{2}\right)$ dapat dilihat pada tabel 2 .

Tabel 2. Hasil Koefisien Determinasi $\left(\mathrm{R}^{2}\right)$

Model Summaryb

\begin{tabular}{|l|r|r|r|c|}
\hline Model & \multicolumn{1}{|c|}{$\mathrm{R}$} & $\mathrm{R}$ Square & \multicolumn{1}{|c|}{$\begin{array}{c}\text { Adjusted R } \\
\text { Square }\end{array}$} & $\begin{array}{c}\text { Std. Error of the } \\
\text { Estimate }\end{array}$ \\
\hline 1 & $.980^{\mathrm{a}}$ & .961 & .923 & 2.79108 \\
\hline
\end{tabular}

a. Predictors: (Constant), Profitabilitas, Perputaran modal kerja

b. Dependent Variable: Kinerja keuangan

Hasil dari regresi diperoleh adjusted $\mathrm{R}^{2}$ sebesar 0,923 , artinya variabel dependen ( $\mathrm{Y}$ ) dalam model yaitu kinerja keuangandijelaskan oleh variabel independen yaitu perputaran modal dan profitabilitas sebesar 92,3\%, sedangkan sisanya sebesar 7,7\% dijelaskan oleh faktor lain di luar model. 


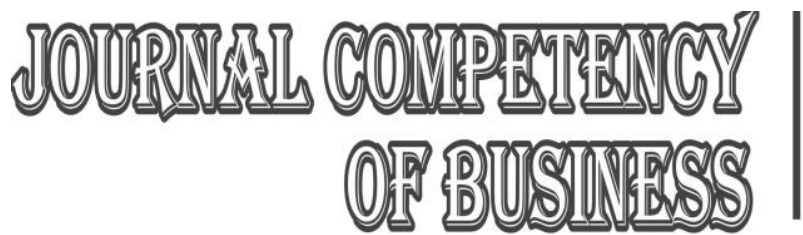

Fakultas Ekonomi, Universitas Cokroaminoto Yogyakarta

\section{Uji F}

Uji statistik F pada dasarnya menunjukkan apakah semua variabel independen yang dimaksud dalam penelitian mempunyai pengaruh secara simultan terhadap variabel dependen (Ghozali, 2016). Nilai sig. F. $\leq 0,05$, maka terdapat pengaruh secara bersama-sama variabel independen terhadap variabel dependen. Hasil uji F dapat dilihat pada tabel 3.

Tabel 3. Hasil uji F

ANOVA $^{\mathrm{a}}$

\begin{tabular}{|c|c|c|c|c|c|c|}
\hline \multicolumn{2}{|c|}{ Model } & $\begin{array}{l}\text { Sum of } \\
\text { Squares }\end{array}$ & $\mathrm{df}$ & $\begin{array}{c}\text { Mean } \\
\text { Square }\end{array}$ & $\mathrm{F}$ & Sig. \\
\hline \multirow{3}{*}{1} & Regression & 387.125 & 2 & 193.563 & 24.847 & $.039^{b}$ \\
\hline & Residual & 15.580 & 2 & 7.790 & & \\
\hline & Total & 402.705 & 4 & & & \\
\hline
\end{tabular}

a. Dependent Variable: Kinerja keuangan

b. Predictors: (Constant), Profitabilitas, Perputaran modal kerja

Diperoleh nilai sig. $=0,039<$ Level of Significant $=0,05$, maka Ho ditolak atau Ha diterima, artinya ada pengaruh secara bersama-sama variabel perputaran modal dan profitabilitasterhadap kinerja keuangan.

\section{Uji t (Pengujian Hipotesis)}

Menurut Ghozali (2016), uji statistik t pada dasarnya menunjukkan seberapa jauh pengaruh satu variabel independen secara individual dalam menerangkan variabel dependen secara parsial. Kriteria hipotesis diterima adalah, jika nilai sig. $\leq 0,05$ dan sebaliknya hipotesis tidak diterima adalah jika nilai sig. > 0,05. Hasil uji t dapat dilihat pada tabel 4.

\section{Tabel 4. Hasil Uji t}

Coefficients $^{\mathrm{a}}$

\begin{tabular}{|c|c|c|c|c|c|c|}
\hline \multirow{2}{*}{\multicolumn{2}{|c|}{ Model }} & \multicolumn{2}{|c|}{$\begin{array}{c}\text { Unstandardized } \\
\text { Coefficients }\end{array}$} & $\begin{array}{l}\text { Standardized } \\
\text { Coefficients }\end{array}$ & \multirow[t]{2}{*}{$t$} & \multirow[t]{2}{*}{ Sig. } \\
\hline & & $B$ & Std. Error & Beta & & \\
\hline \multirow{3}{*}{1} & (Constant) & -643.366 & 110.824 & & -5.805 & .028 \\
\hline & $\begin{array}{l}\text { Perputaran modal } \\
\text { kerja }\end{array}$ & 21.215 & 4.036 & .759 & 5.256 & .034 \\
\hline & Profitabilitas & 660.038 & 111.135 & .858 & 5.939 & .027 \\
\hline
\end{tabular}

1. Pengaruh permutaran modal terhadap kinerja keuangan

Berdasarkan hasil olah data diperoleh nilai sig. $=0,034<$ Level of Significant $=0,05$, maka disimpulkan bahwa ada pengaruh signifikan antara permutaran modal terhadap kinerja keuangan.

2. Pengaruh profitabilitas terhadap kinerja keuangan

Berdasarkan hasil olah data diperoleh nilai sig. $=0,027<$ Level of Significant $=0,05$, maka disimpulkan bahwa ada pengaruh signifikan antara profitabilitas terhadap kinerja keuangan. 


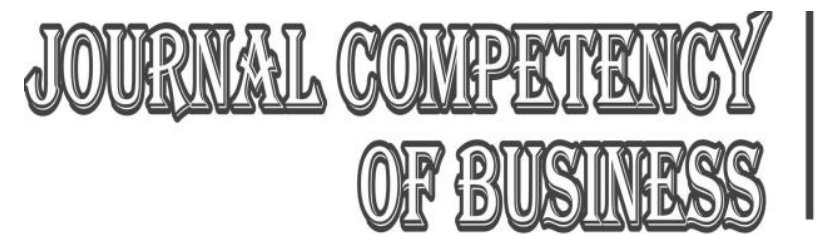

\section{PEMBAHASAN}

Pengaruh perputaran modal kerja terhadap Kinerja Keuangan pada BMT Syariah di Jalan Veteran Yogyakarta.

Berdasarkan hasil olah data diperoleh nilai sig. $=0,034<$ Level of Significant $=0,05$, maka disimpulkan bahwa ada pengaruh signifikan antara permutaran modal terhadap kinerja

keuangan Modal kerja merupakan faktor yang sangat penting dalam suatu perusahaan, karena merupakan modal yang dibutuhkan untuk operasional perusahaan sehari-hari. Modal kerja dapat berupa kas, piutang dan persediaan. Apabila modal kerja dikelola dengan baik maka akan menguntungkan bagi perusahaan karena tidak akan banyak menemui kesulitan dan hambatan dalam menjalankan perusahaan, sebaliknya apabila modal kerja tidak dikelola dengan baik maka akan merusak kegiatan usaha perusahaan.

Hasil penelitian Indah Yuni Astuti (2016) menunjukkan bahwa tingkat perputaran modal kerja berpengaruh signifikan dan positif terhadap kinerja keuangan.Hasil penelitian Indah Yuni Astuti (2016) yang berjudul "Pengaruh Perputaran Modal Kerja Terhadap Kinerja Keuangan".Hasil penelitian menunjukkan bahwa perputaran modal kerja berpengaruh positif signifikan terhadap kinerja keuangan. Hasil analisis korelasi diperoleh $r=0.697$ atau $69.7 \%$ yang berarti korelasi tersebut kuat.

\section{Pengaruh profitabilitas terhadap kinerja keuangan pada BMT Syariah di Jalan Veteran Yogyakarta}

Berdasarkan hasil olah data diperoleh nilai sig. $=0,027<$ Level of Significant $=0,05$, maka disimpulkan bahwa ada pengaruh signifikan antara profitabilitas terhadap kinerja keuangan. Profitabilitas adalah rasio yang digunakan untuk mengukur kemampuan perusahaan dalam menghasilkan laba.Semakin tinggi tingkat keuntungan yang dihasilkan maka semakin baik pula pengelolaan manajemen perusahaan tersebut. Netnetability yang baik akan mempengaruhi kinerja keuangan.

Hasil penelitian Muhammad Fauzi (2015) menunjukkan bahwa profitabilitas berpengaruh terhadap kinerja keuangan Al Hidayaat Kopontren di Kecamatan Pringapus Semarang dari tahun 2009 hingga 2014.

\section{Pengaruh perputaran modal kerja dan profitabilitas terhadap kinerja keuangan pada BMT Syariah di Jalan Veteran Yogyakarta.}

Hasil uji regresu diperoleh nilai sig. $=0,039<$ Level of Significant $=0,05$, maka Ho ditolak atau Ha diterima, artinya ada pengaruh secara bersama-sama variabel perputaran modal dan profitabilitasterhadap kinerja keuangan. Segala upaya untuk menjalankan berbagai aktivitas dan menunjang aktivitasnya membutuhkan modal kerja yang cukup dan BMT Islam di Jalan Laoja Yogyakarta.Ajaran Islam BMT membutuhkan modal kerja yang cukup untuk menjalankan aktivitasnya.Agar perusahaan dapat bertahan dan berfungsi dengan baik maka diperlukan penambahan modal kerja di BMT Syariah. Profitabilitas copontren BMT Syariah digunakan untuk mengetahui berapa keuntungan yang ada dan untuk memprediksi 


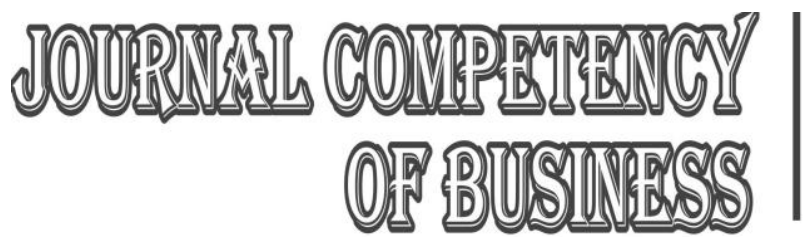

keuntungan yang akan dihasilkan di tahun mendatang dengan aset dan kewajiban (kewajiban jangka pendek dan jangka panjang) yang harus dipenuhi

Hasil penelitian Dwi Noval Bagaskara et al. (2019) menunjukkan bahwa profitabilitas ekonomi dan profitabilitas ekuitas memiliki pengaruh yang signifikan terhadap kinerja keuangan.Dan kinerja keuangan masih dipengaruhi oleh faktor-faktor lain yang tidak terkendali. Hasil penelitian Heppy Shita Larasati (2018) yang berjudul "Pengaruh Modal

Kerja, Tingkat Perputaran Piutang, dan Tingkat Perputaran Persediaan terhadap Profitabilitas Ekonomi Perusahaan Otomotif yang Terdaftar di Bursa Efek Indonesia”. Berdasarkan hasil analisis, model regresi yang diperoleh sesuai untuk menentukan pengaruh modal kerja, tingkat perputaran piutang dan tingkat perputaran persediaan terhadap profitabilitas ekonomi. Modal kerja berpengaruh positif dan penting terhadap profitabilitas ekonomi, sedangkan tingkat perputaran piutang dan tingkat perputaran persediaan tidak berpengaruh signifikan terhadap profitabilitas ekonomi perusahaan otomotif yang terdaftar di bursa efek Indonesia

\section{KESIMPULAN DAN SARAN}

Kesimpulan berdasarkan hasil analisis dan pembahasan yang telah dilakukan adalah sebagai berikut :

1. Ada pengaruh secara parsial perputaran modal kerja terhadap kinerja keuangan pada BMT Syariah di Jalan Veteran Yogyakarta.

2. Ada pengaruh secara parsial profitabilitas terhadap kinerja keuangan pada BMT Syariah di Jalan Veteran Yogyakarta.

3. Ada pengaruh secara simultan perputaran modal kerja dan profitabilitas terhadap kinerja keuangan pada BMT Syariah di Jalan Veteran Yogyakarta

Berdasarkan hasil penelitian dan kesimpulan yang diambil, maka saran - saran yang dapat diberikan adalah sebagai berikut:

1. Untuk BMT Syariah di Jalan Veteran Yogyakarta agar lebih memperhatikan lagi unsur unsur modal kerja yaitu modal kerja netto, piutang dan persediaan untuk meningkatkan kinerja keuangannya.

2. Untuk penelitian selanjutnya agar menambah jumlah variabel dan memperpanjang periode penelitian. Sehingga harapannya didapatkan hasil yang berbeda dan dapat diketahui apakah variabel independenya memiliki pengaruh atau tidak terhadap variabel dependennya. 


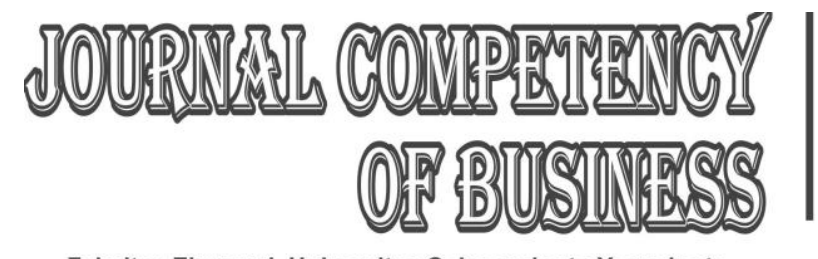

Fakultas Ekonomi, Universitas Cokroaminoto Yogyakarta

\section{DAFTAR PUSTAKA}

Arifin, Zainul. 2009. Dasar-Dasar Manajemene Bank Syariah. Jakarta : Azkia. Publisher.

Astuti, Indah Yuni. 2016. Pengaruh Perputaran Modal Kerja Terhadap Kinerja.Keuangan. JMK, vol. 1, No. 1 Edisi Januari 2016: 1-7.

Bambang Riyanto. 2001. Dasar-dasar Pembelanjaan Perusahaan. BPFE,. Yogyakarta.

Bastian, Indra. 2006. Akuntansi Sektor Publik: Suatu Pengantar. Jakarta: Erlangga.

Dwi Noval Bagaskara et al. (2019). Pengaruh Rentabilitas Ekonomi Dan Rentabilitas Modal Sendiri Terhadap Kinerja Keuangan Perusahaan (Studi Kasus Pada Pt Indofood Sukses Makmur Tbk.). JAWARA : Jurnal Wawasan dan Riset Akuntansi.

Fahmi, Irham. 2011. Analisis Laporan Akuntansi. Bandung: ALFABETA.

Fauzi, Mohammad Nur dan Suhadak.(2015). Pengaruh Kebijakan Dividen dan Pertumbuhan Perusahaan terhadap Struktur Modal dan Profitabilitas Studi pada Sektor Mining yang Terdaftar di Bursa Efek Indonesia Periode 2011-2013. Jurnal Administrasi Bisnis, 24 (1), $1-10$.

Ghozali, Imam. 2016. Aplikasi Analisis Multivariete Dengan Program.IBM SPSS 23 (Edisi 8).Cetakan ke VIII.Semarang : Badan Penerbit.

Harahap, Sofyan Syafri. Drs., 2007. Analisis Kritis Atas Laporan Keuangan,.Cetakan ke-7. Jakarta: PT Raja Grafindo Persada.

Heppy Shita Larasati (2018). Pengaruh Modal Kerja, Perputaran Piutang, Dan Perputaran Persediaan Terhadap Rentabilitas Ekonomi Pada Perusahaan Automotive Yang Terdaftar Di Bursa Efek Indonesia. Tesis. Digital Repository UPN Veteran Jatim

Husnan, Suad. 1995. Manajemen Keuangan: Teori dan Penerapan. Edisi Ketiga. Cetakan Kedua. BPFE.Yogyakarta.

Indriyo, Gitosudarmo dan Basri.(2002). Manajemen.Keuangan. Yogyakarta: BPFE. Munawir, S.2000. Analisa Laporan Keuangan. Yogyakarta: Liberty. 